\title{
A Construção Histórica Contextual da Termodinâmica para o Ensino Médio
}

\author{
The Historical Contextual Construction of Thermodynamics for Middle \\ School
}

Geilson Rodrigues da Silva (geilsonrodrigues367@gmail.com)

Universidade Federal de Mato Grosso do Sul (UFMS)

Nádia Cristina Guimarães Errobidart (nacriguer@gmail.com)

Universidade Federal de Mato Grosso do Sul (UFMS)

Resumo: As pesquisas em História da Ciência primam pela necessidade de utilização de estratégias didáticas que abordem o processo de construção dos conhecimentos científicos como uma forma de propiciar o entendimento dos procedimentos básicos de investigação da produção de conhecimentos científicos contribuindo assim para a compreensão da Natureza da Ciência. Diante disso, temos como objetivo apresentar o desenvolvimento da Termodinâmica em uma perspectiva contextual de Natureza da Ciência por entendemos que tal perspectiva contribuiu para evidenciar a ciência como construção humana. Para isso, desenvolvemos um texto que é um produto didático oriundo de um Mestrado Profissional em que apresentamos o desenvolvimento da Termodinâmica em consonância com a Revolução Industrial a partir da mobilização de conhecimentos disciplinares oriundos de diferentes fontes conceituais. No decorrer das discussões o docente pode destacar a importância da Revolução Industrial para o aperfeiçoamento das máquinas térmicas e as transformações sociais que o emprego das máquinas promoveu na sociedade. Desse modo, o texto permite demonstrar a ciência como um processo de construção humana passível de influências do seu contexto tais como a necessidade social de aperfeiçoamento das máquinas térmicas.

Palavras-chave: Revolução Industrial; História da Termodinâmica; Abordagem Contextual.

\begin{abstract}
Research in the History of Science stands out for the need to use didactic strategies that approach the process of construction of scientific knowledge as a way to propitiate the understanding of the basic procedures of investigation of the production of scientific knowledge, thus contributing to the understanding of the Nature of Science. Therefore, we aim to present the development of Thermodynamics in a contextual perspective of Nature of Science because we believe that such perspective has contributed to highlight science as human construction. To this end, we have developed a text that is a didactic product coming from a Professional Master in which we present the development of Thermodynamics in line with the Industrial Revolution from the mobilization of disciplinary knowledge from different conceptual sources. During the discussions the teacher can highlight the importance of the Industrial Revolution for the improvement of thermal machines and the social transformations that the use of machines has promoted in society. In this way, the text allows us to demonstrate science
\end{abstract}


as a human construction process susceptible to influences from its context such as the social need to improve thermal machines.

Keywords: Industrial Revolution; History of Thermodynamics; Contextual Approach

\section{INTRODUÇÃO}

Nas últimas três décadas vêm aumento as discussões na área de Ensino de Ciências, em torno da utilização de teorias construtivistas, que primem pela superação do ensino tradicional. As teorias sinalizam a necessidade de superar a abordagem de conteúdos dissociados da experiência e do contexto social dos estudantes, transmitidos pelos docentes como verdades absolutas, as quais devem ser absorvidas pelos estudantes a partir da repetição de exercícios (LEÃO, 1999).

Nesse contexto considera-se a necessidade de utilização de estratégias didáticas que abordem o processo de construção dos conhecimentos científicos como uma forma de propiciar o entendimento dos procedimentos básicos de investigação da produção de conhecimentos científicos, contribuindo para que os estudantes desenvolvam o pensamento crítico, reflexivo e criativo (FORATO, PIETROCOLA; MARTINS, 2011).

Uma possibilidade é a utilização da História da Ciência no contexto educacional, como uma estratégia viável para discutir o processo de construção da ciência, e suas transformações e que ele influência a sociedade e por ela é influenciado (MOURA; SILVA, 2014; MOURA; GUERRA, 2016; SANTOS, 2018). As pesquisas supracitadas apontam que não é possível dissociar a ciência e seus possíveis desdobramentos tecnológicos da cultura humana. É necessário considerar que a construção dos conhecimentos científicos perpassa a superação da visão reducionista da ciência, como um mero amontado de saberes específicos. Ela integra um escopo maior que engloba também a produção de teorias, metodologias, refletindo os aspectos humanísticos da sua construção e que estão imbricados na representação simbólica que o homem constrói dos fenômenos naturais, a partir de elementos que são próprios do seu universo cultural (ALVIN; ZANOTELLO, 2014).

Diante desses aportes, que representam a ciência como um processo de construção humana e passível de influências, temos como objetivo apresentar o desenvolvimento histórico da Termodinâmica utilizando uma perspectiva contextual, isso porque, ela é abordada predominantemente de forma matematizada e afastada do seu contexto 
histórico de produção. Dessa forma, a perspectiva contextual, permite uma reconstrução de episódios históricos levando em considerações tanto os aspectos racionais, como a experimentação, a formulação de hipóteses, como os fatores sociais, o interesse econômico. No caso do presente estudo que é um produto em forma de texto oriundo de um Mestrado Profissional possibilita uma discussão do emprego e aperfeiçoamento das máquinas térmicas que foram importantes para a consolidação da Termodinâmica sendo que iniciamos a discussão a partir dos primórdios da primeira Revolução Industrial, até a construção das Leis da Termodinâmica, buscando evidenciar a influência da sociedade no desenvolvimento científico, bem como, as transformações sociais que as máquinas térmicas provocaram na sociedade da época.

\section{ABORDAGEM CONTEXTUAL DE NATUREZA DA CIÊNCIA}

Nas últimas três décadas é expressivo o quantitativo de pesquisas que buscam inserir a discussão sobre a Natureza da Ciência no Ensino de Ciências, de forma a promover uma abordagem contextual do processo de construção do conhecimento. Isso permite que os alunos construíssem uma concepção mais ampla sobre o desenvolvimento científico e seus processos de produção, divulgação, revisão e validação (SANTOS, 2018).

Segundo Moura; Silva (2014) a Natureza da Ciência envolve a construção de saberes a partir de múltiplas lentes tais como a epistemológica, a filosófica, a histórica e cultural da ciência. Elas contribuiriam para uma formação integral dos alunos, no sentido de desenvolver neles habilidades críticas, reflexivas que possibilitem entender a importância da ciência na sociedade contemporânea. Isso resultaria no decréscimo das concepções errôneas sobre ciências no ensino da Educação Básica, promovendo uma alfabetização científica, um dos objetivos da Educação na contemporaneidade. Assim é possível desmistificar concepções errôneas do fazer científico e da ciência, como algo com forma estática, dogmática e desvinculada dos aspectos históricos da sua construção.

Nesse sentido, a perspectiva contextual possibilita dar sentido ao fazer científico e seu emprego como estratégia de ensino ou de conteúdo mantendo-se alinhado aos objetivos pedagógicos da sua utilização na Educação Básica. E pensando nesse alinhamento com os propósitos da Educação Básica que temos de ter metas modestas ao trabalhar a História da Ciência articulada com a Natureza da Ciência já que não estamos 
formando cientistas. Porém, mesmo com metas modestas, é possível levar a discussão da produção do conhecimento científico para os estudantes, demonstrando assim que essa produção traz marcas do contexto social e cultural em que foi desenvolvida. Essa discussão deve explicitar a estrutura epistemológica que alicerça a produção do conhecimento humano e suas relações com o imaginário sociocultural, no qual os produtores do conhecimento estavam imersos e esse processo de imersão que diferencia historicamente a ciência que é desenvolvida em um período de outra (FORATO, PIETROCOLA; MARTINS, 2011).

Diante desses apontamentos e considerando a relevância da História da Ciência para o Ensino de Ciências alinhamos a proposta de El-Hani (2006), acerca da articulação entre a História da Ciência e a Natureza da Ciência em uma abordagem contextual com uma forma de realizar essa abordagem que de acordo com o autor:

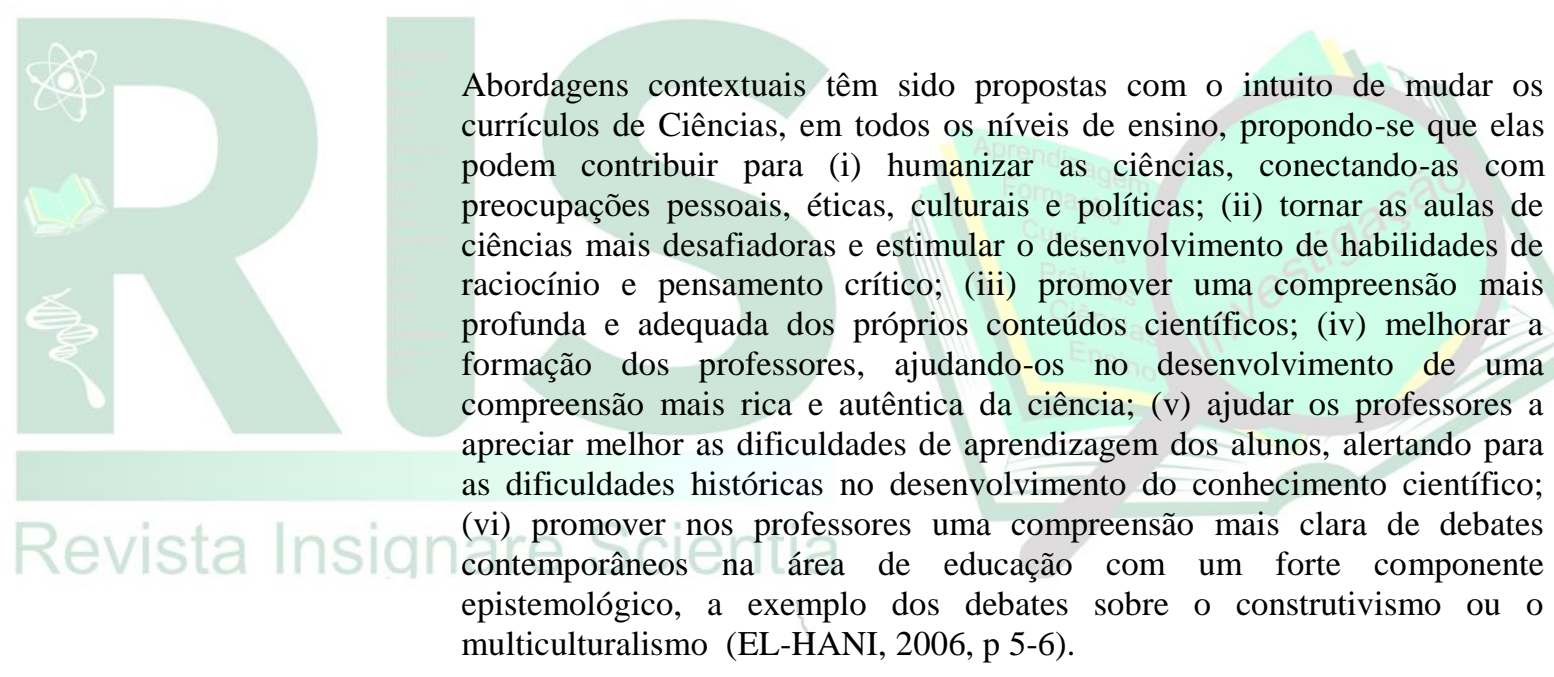

Os aspectos listados na citação anterior sobre a inserção da História da Ciência no Ensino de Ciências, almejado uma abordagem contextual, são compatíveis com sugestões listadas por autores como Matthews (1995), McComas (1998), Gil Pérez et al. (2001), Allchin (2004).

Uma discussão pautada nos aspectos históricos contextual evidencia como evoluiu determinados conhecimentos, diminuindo assim as chances de os estudantes desenvolverem concepções estáticas, dogmáticas acerca da Natureza da Ciência (CARVALHO; GIL-PÉREZ, 2011).

\section{O DESENVOLVIMENTO DA TERMODINÂMICA A PARTIR DE UMA ABORDAGEM CONTEXTUAL DE HISTÓRIA DA CIÊNCIA}

Recebido em: 25/05/2020

Aceito em: 19/09/2020 
Discutir o desenvolvimento da Termodinâmica em consonância com a Revolução Industrial requer a construção de uma representação interdisciplinar ${ }^{1}$ que mobiliza conhecimentos disciplinares oriundos de diferentes fontes conceituais tais como a Física, Química, Sociologia, História, dentre outras. Iniciamos a sequência discursiva convidando-o a mobilizar conhecimentos disciplinares geralmente explorados por professores de História, sobre a Revolução Industrial e o desenvolvimento das máquinas térmicas.

No decorrer das discussões o docente pode destacar a importância da Revolução Industrial para o aperfeiçoamento das máquinas térmicas e as transformações sociais que o emprego delas promoveu na sociedade. Pode-se abordar conhecimentos sobre: as aplicações das máquinas térmicas no setor militar; as contribuições de Sadi Carnot para a compreensão do calor; a Teoria do Calórico; o Cartismo e Ludismo; James Prescoule Joule e as suas contribuições para a determinação do equivalente mecânico do calor; o desenvolvimento da Termodinâmica a partir das contribuições de Helmholtz, Clausius, Thomson para a formulação da Termodinâmica.

No momento destinado as discussões consulta-se o texto para informação sobre a utilização militar das máquinas térmicas, com o exemplo do navio a vapor. $\mathrm{O}$ docente pode destacar que nessa época o império francês, desejava aumentar suas colônias, entrou em guerra com a Inglaterra e com as demais potências europeias. Não obteve resultado satisfatório, pois foi derrotada pela aliança da Inglaterra com as potências europeias. No contexto da discussão o docente pode chamar a atenção dos alunos para o fato que um dos motivos dessa derrota francesa pode ser atribuído aos resultados obtidos por Nicolas Léonard Sadi Carnot, relacionado ao melhoramento da máquina térmica, aspecto que também impulsou a economia do país.

As relações entre a sociedade e a ciência é sugerido discutir a partir do movimento de revolta do Cartismo e do Ludismo, permitindo uma aproximação com a História. Nessa discussão destaca-se a importância que as máquinas térmicas tinham para a sociedade inglesa da época, utilizando como exemplo a cidade de Manchester, muito industrializada principalmente pelos aspectos geográficos que a tornavam propícia para a instalação de novas fábricas.

\footnotetext{
1 Adotamos no presente trabalho o entendimento de Fourez (2008) para a interdisciplinaridade como aquela que apresenta um percurso para a construção de um novo conhecimento oriundo de um diálogo de saberes disciplinares visando a sua integração e também da negociação entre os distintos pontos de vista.
}

Recebido em: 25/05/2020

Aceito em: 19/09/2020 
É nesse cenário que o docente insere a discussão sobre Joule e o desenvolvimento de estudos pautados na experimentação em relação aos fenômenos magnéticos e elétricos, que antecederam os referentes aos da natureza do calor, impulsionados por interesses técnicos e científicos. O docente solicita aos alunos que se atentem as informações contidas no texto sobre como Joule desenvolveu seus experimentos e a posterior contribuição deles, para a elucidação do equivalente mecânico do calor.

Em seguida, o docente pode orientar a discussão sobre os conflitos militares advindos da utilização das máquinas térmicas e o quanto eles foram importantes para consolidar a unificação da Alemanha e da Itália. Destaca-se ainda como consequência o surgimento dos centros politécnicos que formavam mão de obra qualificada para o exército. Fechando a discussão, ressalta-se as contribuições de Helmholtz, Clausius e Thomson para o desenvolvimento das leis da Termodinâmica.

\subsection{Revolução Industrial e o desenvolvimento das Máquinas Térmicas}

A Revolução Industrial inglesa desencadeou uma revolução social a partir de mudanças importantes nas técnicas de produção, com causas e efeitos marcantes para a sociedade, que mediante a fortalecimento do capitalismo se depara com duas classes revolucionárias e antagônicas: burguesia e o proletariado (LIMA; OLIVEIRA NETO, 2017).

Essa revolução representa marco histórico importante aspecto externalista, que influenciou diferentes setores da sociedade, dentre os quais os associados com desenvolvimento do processo científico nos séculos XVIII e XIX. Ela teve início na Inglaterra e se internacionalizou no decorrer do século XIX, processo, que não ocorreu do dia para a noite e que resultou em profundas transformações econômicas e sociais, a partir desse período. Elas impulsionaram modificações nos meios de produção agrícola, principalmente, que culminaram numa nova concepção das relações de trabalho, impulsionada pelo crescimento econômico acelerado e a disponibilidade de novas técnicas industriais.

Essas modificações foram muito significativas no âmbito das propriedades rurais e da produção agrícola, não só pela mudança da ocupação da terra para dar conta de suprir a crescente necessidade do desenvolvimento econômico e atividades industriais. Era imperativo para o processo garantir o abastecimento das populações urbanas e o 
funcionamento das fábricas, que as propriedades que produziam para subsistências familiar investisse em monoculturas. Surgiam assim os minifúndios e latifúndios, com estreita relação com a Revolução Industrial, sendo indiscutível que para compreendermos o industrialismo é indispensável ter em conta o problema agrário, como propriedade da terra ou produção agrícola (SANTOS, 2004).

Antes do início do processo de industrialização a Inglaterra era um país com uma economia fragilizada, que não visava lucros, e que estava longe de ser próspera. A população, em geral, vivia sob o regime dos senhores feudais, donos de grandes propriedades rurais, nas quais seus servos plantavam para garantir a subsistências. Esses servos cuidavam das extensas propriedades, plantando e colhendo as lavouras (OLIVEIRA, 2017).

No decorrer do período que marcou o desenvolvimento da industrialização inglesa as relações feudais, que ainda persistiam no contexto rural, aos poucos davam lugar as grandes propriedades adquiridas pela burguesia: os minifúndios e latifúndios. Com a mudança de proprietários os antigos servos se viram obrigados a migrar da forma de agricultura de subsistência para a comercial, garantindo assim uma produção com menor gasto, aumento da produção alimentícia, expansão do comércio atendendo aos anseios da burguesia que buscava a exportação do excedente da produção.

Recordamos que a burguesia era a classe social dominante no contexto histórico em que ocorreu a Revolução Industrial. Ela detinha os meios de produção e apresentava elevada influência no meio político, fatores que justificavam o monopólio dos meios de produção e favoreciam a exploração da classe trabalhadora, que mantinha as indústrias em funcionamento (MIGLIOLI, 2010). Ela almejava uma economia forte e crescente, que visasse lucros atendendo os seus interesses e que garantisse o controle social sobre a classe trabalhadora, que mantinha o crescente processo de industrialização das fábricas.

A industrialização inglesa encontrou condição política e social favorável pois, ao contrário de outros países da Europa, ela tinha vivenciado seu último grande conflito no século XVII, período da Revolução Gloriosa. Sua privilegiada posição geográfica, seu território numa ilha, além de dificultar a invasão de outras potencias em processo de industrialização possibilitava o controle dos mares no século XVIII: os portos de Bristol, Glasgow e Liverpool concentrava a circulação da matéria prima necessária para 
o funcionamento da indústria algodoeira e, principalmente, o tráfico de escravos, que era a principal fonte do capital acumulado pela burguesia (HOBSBAWM, 2000).

Como não estava envolvida em conflitos, guerreando, a Inglaterra expandiu-se com a ampliação dos mercados e a crescente necessidade de mais mercadorias. Desenvolveu sua indústria bélica, principalmente a marinha, fator que possibilitou tornar-se centro econômico na época da Revolução Industrial, tendo o controle do mercado (HOBSBAWM, 2000). O desenvolvimento dessas indústrias solicitou substituição da manufatura pela maquinofatura, buscando suprir essa necessidade e atender a demanda do mercado mundial. As máquinas, incorporadas incialmente na indústria têxtil, revolucionaram a produção industrial e isso resultou no aumento da demanda por fontes de energia como o carvão mineral, encontrado em abundância no subsolo da Inglaterra (PASCOAL, 2016).

É nesse ponto que iniciamos a integração de conhecimentos disciplinares comumente explorados por professores de Física, que abordam os princípios de funcionamento de uma máquina térmico e algumas vezes discorrem sobre os primeiros equipamentos construídos com a finalidade de atender uma demanda social, associada a revolução industrial. Entretanto, ao discorrer sobre seu funcionamento muitas vezes não exploramos a fonte de energia empregada para tal: o carvão vegetal e mineral (SILVA; ERROBIDART, 2020).

A Inglaterra resolveu o problema da escassez de carvão vegetal, após destruir suas florestas, com o pioneirismo no desenvolvimento de uma técnica que eliminava os voláteis e grande parte do enxofre e possibilitava a utilização do carvão mineral como fonte de energia. Atrelado a esse desenvolvimento o aprimoramento de máquinas térmicas que utilizavam o vapor e não o carvão diretamente, transformou a Inglaterra numa grande exportadora de ferro e aço, empregado em outros países principalmente nas indústrias bélicas.

A Inglaterra no período da primeira Revolução industrial possuía muitas jazidas de carvão no seu subsolo e muitas minas espalhadas por seu território: uma ilha. Para aumentar a produção do carvão mineral as minas, local de onde ele era retirado, ficavam cada vez mais profundas e geralmente tinham infiltrações nos seus estágios finais, pois as escavações cortavam os lenções freáticos. Algumas vezes, como a profundidade ultrapassava o nível do mar a situação era agravada a sociedade que dependia disso 
passou a enfrentar uma situação problema que culminou no desenvolvimento das máquinas térmicas e posteriormente da Termodinâmica: como retirar a água que se acumulava nas minas, devido as infiltrações, e prejudicava a extração de carvão mineral, do subsolo inglês?

A quantidade de água no interior das jazidas era uma situação problema relevante vivenciada pela sociedade da época da primeira revolução industrial e a busca por soluções que contribuíssem para a retirada da água das minas impulsionou o desenvolvimento das máquinas térmicas inglesas. O desenvolvimento da técnica tinha por objetivo suprir a necessidade de retirar esse excesso de água do interior das minas, deslocando-a para fora da jazida, possibilitando assim a fonte de energia necessária para manter as industrias em funcionamento e mais segurança aos trabalhadores que se dedicavam a extração do carvão mineral (BRAGA; GUERRA; REIS, 2005).

Um dos primeiros equipamentos visando atender essa finalidade foi construído e patenteado em 1698, pelo militar Thomas Savery, o qual empregou o princípio de funcionamento de uma máquina térmica à vapor, que remete aos dispositivos de êmbolo-pistão, construídos em 1690 por Denis Papin.

O sistema de embolo-pistão desenvolvido por Papin, foi implementado na máquina térmica a vapor por meio de um cilindro, no qual deslizava-se um pistão interligado por uma barra. Uma pequena quantidade de água era acondicionada no interior do cilindro, que ao ser aquecido transformava a água em vapor, impulsionando o movimento de subida do pistão, para ser preso por uma presilha. $\mathrm{O}$ cilindro era então resfriado e o vapor no interior se condensava e quando a presilha era solta o pistão era empurrado para baixo por ação da pressão atmosférica, levantando assim o peso (SUARÉZ, 2011). Savery empregou um sistema semelha no equipamento que construiu, conforme detalhado na Figura 1. 
A máquina de Savery, tinha um princípio de funcionamento simples, porém era inovador para sua época pois, ainda não tinha sido construído até então uma máquina que aproveitasse o vácuo.

A água contida na caldeira (1) quando aquecida ao ponto de fervura, transformava-se em vapor de água, o qual adentrava o recipiente (2), após passar por uma tubulação controlada por uma válvula (3). Esse vapor de água ao entrar em contato com a superfície resfriada pela água que estava armazenada no recipiente (6), despejada sobre o recipiente (2) se condensava. Dessa forma se produzia um vácuo parcial que era utilizado para elevar à água do interior da mina (4), fazendo uso da pressão atmosférica que atua na superficie da água no interior da mina (4), Essa água é transferida para o meio externo, passando pela válvula $\mathrm{A}$, impulsionando a água para fora da mina por meio do vapor, passando pelo duto (5), abrindo então a válvula $\mathrm{B}$ (adaptado de SUARÉZ, 2011).

Figura 1: Máquina de Savery e seu funcionamento. Fonte: Adaptado de SUARÉZ, 2011, p. 37.

Apesar de resolver a situação problema em pequenas profundidades, a máquina de Savery exigia o aumento da pressão conforme aumentava-se a profundidade da mina e isso resultava na explosão da caldeira, provocando acidentes sérios. Ela também apresentava problemas com relação as tubulações, que assim como a caldeira trabalhava de forma aceitável em baixas pressões, deslocando a água por poucas dezenas de metros (FREITAS, et al, 2010).

Como as minas ficavam cada vez mais profundas e a máquina de Savery era ineficiente para explorar grandes profundidades, muitos técnicos e inventores continuavam buscando respostas para a situação problema. Vultuosos recursos financeiros eram oferecidos para aqueles que sinalizavam sucesso nas tentativas de retirar a água das profundezas das minas de carvão mineral.

Outro inventor destacado na abordagem disciplinar sobre máquinas térmicas é Thomas Newcomen, que passou a empregar um sistema com um cilindro e um pistão móvel, proporcionando melhor rendimento e mais segurança. Entretanto, seu funcionamento demandava alto consumo de carvão mineral e o superaquecimento também resultava em quebras frequentes.

O reparo de uma máquina térmica, com peças de grandes proporções não poderia ser realizado em oficinas improvisadas e rudimentares, solicitava espaços maiores e com mais instrumentos, tais como as construídas para atender necessidades de cursos de 
engenharia, na universidade Glasgow na Escócia (BERNAL, 1951). Em um desses espaços trabalhava o construtor de instrumentos James Watt. Como frequentemente enviavam para a oficina na qual trabalhava essas máquinas ele começou a sobre seu funcionamento para consertá-las e, empregando seus conhecimentos da prática profissional, construiu a máquina indicada na Figura 2.

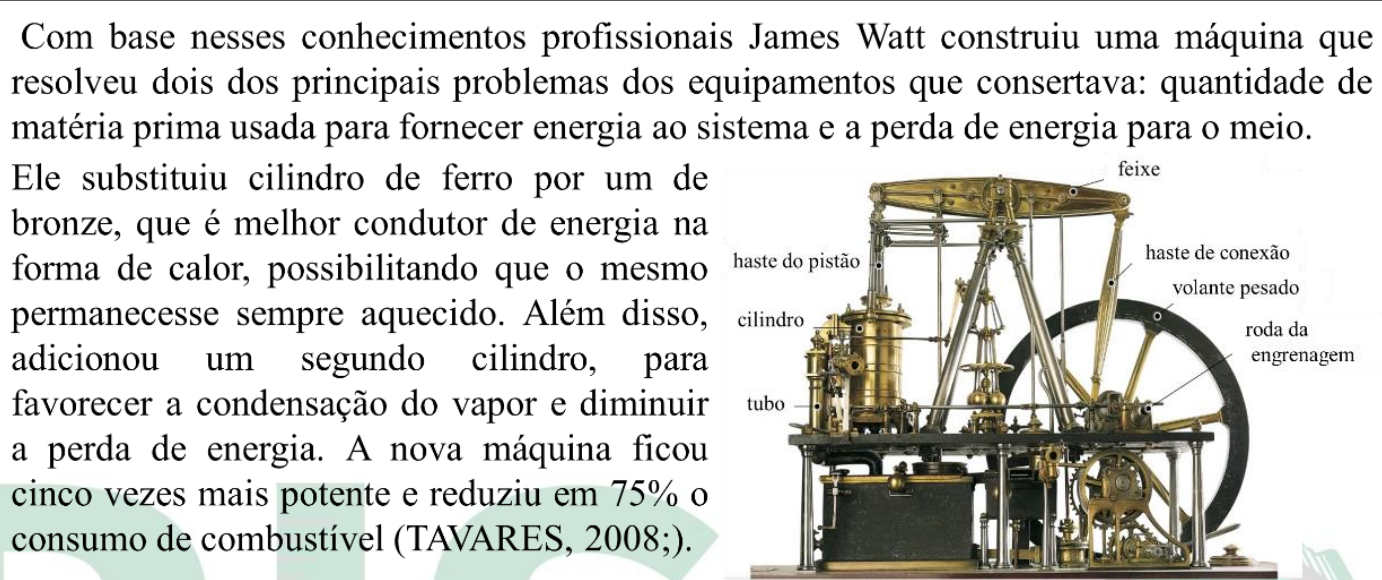

Figura 2: Máquina de Watt e o seu funcionamento. Fonte: Adaptado de:

https://www.dkfindout.com/uk/science/amazing-inventions/steam-engine/. Acesso em: $18 / 01 / 2018$.

Apesar da situação problema principal ser o acúmulo de água no interior de minas com grande profundidade, elas foram empregadas em diversos setores da sociedade, como na área militar: a máquina de brocar canhões utilizadas pelo exército inglês e as que eram utilizadas pela marinha da Inglaterra nos navios movidos a vapor. Essas embarcações eram mais eficientes do que os navios de vela que utilizavam da força dos ventos, o que resultou na ampliação da quantidade de soldados transportados e de canhões (PASCOAL, 2016).

No estudo disciplinar das máquinas térmicas destacamos também a contribuição de Nicolas Léonard Sadi Carnot, filho de um importante militar francês que se interessou pelo estudo das máquinas térmicas, pois acreditava que era importante aperfeiçoar os equipamentos franceses para superar o poderio militar inglês. A situação problema que o levou a estudar as máquinas térmicas não era a mesma da Inglaterra. Ele não queria resolver o acúmulo de água no interior das minas, sua motivação era relacionada a aplicação da máquina de Watt no contexto militar.

Ao analisar a máquina térmica Carnot inferiu que o calor flui entre um corpo que possui uma temperatura maior para outro corpo, com temperatura menor, não ocorrendo 
em sentido contrário, sendo que o calórico só poderia ser reestabelecido no equilíbrio, se não houvesse atrito. Este fato é um dos principais responsáveis pelo baixo rendimento das máquinas. Entretanto Carnot empregava o calórico para elucidar a produção da potência motriz que segundo ele, o calórico não era consumido nesse processo, mas ocorria o transporte do calórico de um corpo quente para o frio (PASCOAL, 2016).

A teoria do calórico, geralmente explorada como conhecimento disciplinar da física e da química, apresentava um arcabouço postulacional que primava: (a) ele é um fluído elástico que permeia as substâncias, sendo que suas partículas constituintes se repelem mutuamente e são atraídas pelos constituintes de outras substâncias; (b) ele é sensível às variações de temperatura, escoando de um corpo quente para um mais frio, quando colocados em contato térmico; (c) ele não pode ser criado durante um processo físico, nem destruído sendo, portanto é conservado. Isto mostra que o calórico tem massa a qual se conserva durante um processo físico; (d) Existem dois tipos de calórico: sensível que está associado à variação da temperatura e o latente que não apresenta alteração de temperatura (PÁDUA; PÁDUA; SILVA, 2009).

Carnot apesar de utilizar o calórico na explicação dos processos térmicos, seus resultados não foram aceitos por boa parte da comunidade científica, pois nesse período aceitabilidade das teorias dependiam do respaldo empírico e do formalismo matemático (PASCOAL, 2016).

Nesse período podemos considerar que a sociedade influenciou o desenvolvimento científico, pois o aprimoramento das máquinas térmicas requisitava mais que conhecimentos práticos e a comunidade científica contribuiu para o bem social, estudando sobre o calor e como ele poderia solucionar problemas do dia a dia. Os aspectos internalistas e externalistas convergem em busca de um resultado comum interligado: o desenvolvimento da termodinâmica e a aplicação da energia na forma de calor. 
$\mathrm{O}$ resultado

desse

desenvolvimento

mutuo

resultou

em transformações

significativas na sociedade, como indicado na Figura 3.

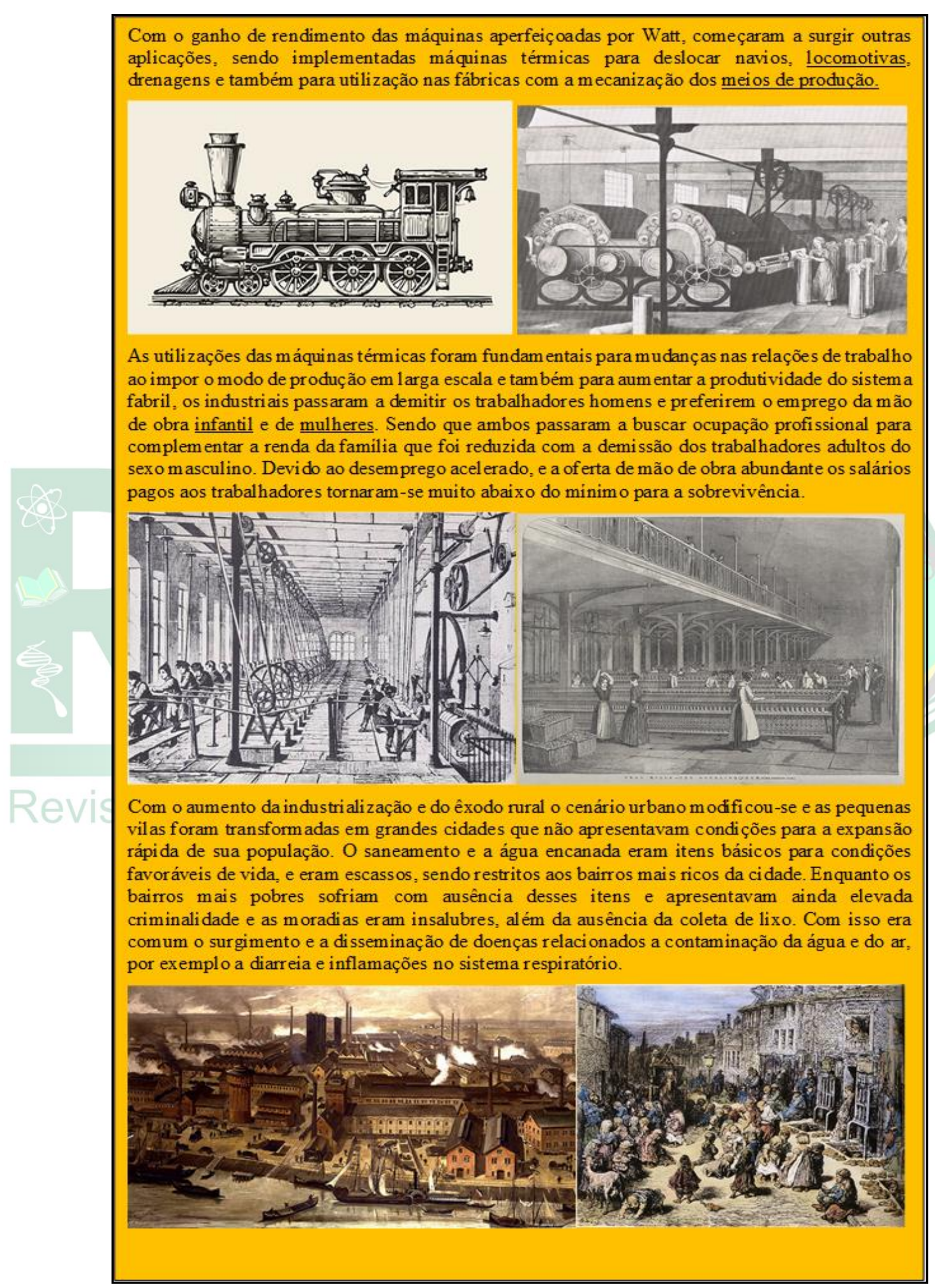

Figura 3: Consequências da utilização das máquinas térmicas na sociedade.

Fonte: Elaborado pelos autores.

Recebido em: 25/05/2020

Aceito em: 19/09/2020 
Enquanto as discussões nas academias de ciências acerca do calor aumentavam, a sociedade era impactada com a crescente mecanização dos meios de produção e consequente acúmulo de capital, resultante da exploração da mão de obra da classe operária. Tornaram-se constantes manifestações como a indicada na Figura 4, só que após a revolta dos "quebradores de máquinas" os manifestantes constataram que não eram as máquinas que os prejudicavam, mas sim seus proprietários.

Por volta de 1811, o proletariado revoltou-se contra a classe opressora detentora dos meios de produção. Liderados por Ned Ludd, os operários invadiram as fábricas e destruíram as máquinas, e ficaram conhecidos como "quebradores de máquinas".

O movimento do Ludismo, como ficou conhecido, foi uma das primeiras revoltas da classe operária contra os avanços tecnológicos. Este movimento desorganizado e violento era contemplado por esquadrões ludistas que transitavam pelas ruas inglesas portando martelos, pistolas e outros objetos utilizados para concretizar seus objetivos.

Figura 4: Revolta do proletariado buscando melhores condições de trabalho. Fonte: Adaptado de LHULLIER, 2013, p.14.

Nos centros industriais como a cidade de Manchester afloravam diferentes problemas sociais, muitos decorrentes do processo de exploração do trabalho humano em condições subumanas, com enriquecimento da classe burguesa. Nessa cidade existia muitos atrativos comerciais, devido à expansão da industrialização e esse foi um dos fatores que atraiu a família de James Prescott Joule.

A família de Joule, ao chegar na cidade Manchester, aplicou seus recursos financeiros na implantação de uma fábrica de cerveja: investimento lucrativo considerando que era grande o consumo de bebidas alcoólicas na cidade, visto que era mais saudável beber cerveja que água. Os poços e fontes de água, própria para consumo da população urbana eram raras, pois a maioria estava contaminadas por dejetos humanos e industriais, lançado nas vias públicas, dada a precariedade das cidades.

A situação problema que impulsionou os estudos iniciais de Joule estava pautados em princípios técnicos, no que tange o calor produzido na passagem de corrente elétrica. Suas ideias de Joule sinalizavam que o calor assim produzido era oriundo do efeito mecânico. 
Para auxiliar em seus estudos Joule construiu um aparato experimental, indicado na figura 5, que era composto em uma roda de pás dispostas horizontalmente em uma cuba com água. Essa roda era movimentada pela ação de um molinete ligado por duas massas. A queda das massas deslocava as pás por meio do molinete e a fricção gerada pelo movimento das pás aquecia a água (SOUZA; SILVA; ARAUJO, 2014).

Para estudar de forma mais aprofundada o calor, Joule
construiu um aparato experimental, que possuía duas
polias (a) e um rolo em (b), o eixo do aparelho de atrito
na vertical, em (c) o eixo do aparelho do atrito na
horizontal, em (d) é um vaso de cobre em que o
aparelho, girando firmemente, equipado com dois
buracos na tampa, um para a inserção do eixo, e o outro
para a inserção do termômetro (SOUZA, SILVA
ARAUJO, 2014).

Figura 5: Esquema de um dos aparatos utilizados por Joule no estudo do calor. Fonte: Souza; Silva; Araujo, p.4, 2014.

A cuba, indicada na figura pela letra (d) atuava como um calorímetro sendo composta por um vaso cilíndrico revestido de cobre, que tinha em seu interior 4 placas dispostas verticalmente fixadas em intervalos de $90^{\circ}$ e um agitador de latão com 8 pás presas em um eixo vertical, isolado por um revestimento de madeira, que atuava para minimizar as perdas de calor por condução. Eram então colocados objetos com massa de $13 \mathrm{~kg}$, sendo suspensas por cordas em um eixo interligado a uma roldana. As roldanas moviam-se fazendo girar o eixo vertical da roda de pás, depois de caírem de uma altura de 1,50 metros, eram realocados no eixo e caíram novamente (DÍAZ, 2014).

Joule estipulou a relação entre a produção de calor a partir de uma corrente do tipo voltaica obtendo medidas precisas da temperatura da água em contato com uma porção em formato de espiral de um circuito, com termômetros de elevada sensibilidade, permitindo realizar a determinação com precisão do calor específico do cobre e do latão da roda de pás (SOUZA; SILVA; ARAUJO, 2014).

Apesar dessa investigação experimental o trabalho de Joule não foi conclusivo para determinar a existência ou não do calórico, pois a comunidade de cientistas, não aceitavam os resultados frágeis de Joule e exigiam mais resultados e de mais 
experimentos que elucidasse a natureza calor, para que as discussões da origem dinâmica do calor, seja aceita (CALADO, 2011).

Sendo assim, Joule realizou outra série de experimentos para elucidar que o calor obtido seria de origem dinâmica. Para isso Joule realizou experimentos semelhantes aos já efetuados, por ele, mas dessa vez utilizou de jogos diferentes de palhetas para a roda de pás: Estas passaram a ser compostas por uma de latão, uma de ferro forjado e a última um liga de ferro e carbono. E por sugestão de Michael Faraday, Joule realizou o experimento em banho de mercúrio, devido este elemento apresentar baixa capacidade calorífica na água, com essa nova série de experimentos Joule conseguir demostrar de forma mais clara a relação o trabalho e o calor que não dependia dos materiais e dos processos utilizados. Ele ainda teve êxito em obter o valor para a constante J de 4,154 $\mathrm{J} / \mathrm{cal}$, além de inferir que a energia potencial poderia ser transformada em energia cinética e a energia cinética seria transformada em calor, com isso o calor e a energia mecânica estariam relacionados (PÁDUA; PÁDUA; SILVA, 2009).

Com o aperfeiçoamento das máquinas térmicas essas passaram a desempenhar cada vez mais um papel central nos conflitos militares e devido à necessidade militar os centros científicos, passaram também a englobarem os colégios militares que se associaram aos centros politécnicos ${ }^{2}$ para a formação de engenheiros, técnicos e médicos com capacidades de atuar no exército.

É nesse ambiente universitário que Hermann Ludwig Ferdinand von Helmholtz, recebe a sua formação inicial em medicina, além de ter estudado Física e Filosofia. Buscando obter vantagens militares, Helmholtz analisou o equivalente mecânico do calor buscando uma aplicação mais ampla de tal forma que um corpo apresenta energia mecânica se este pode realizar trabalho. Essas reflexões podiam ser utilizadas tanto para máquinas, como para a natureza o que incluía os seres humanos, pois qualquer gasto de energia tem como consequência o trabalho e qualquer trabalho realizado resultaria no consumo de energia. Deste modo, o trabalho passaria ser um fenômeno quantitativo que era representado por um conjunto de equações matemáticas. Além disso, as análises de Helmholtz no estudo do calor levaram este cientista a inferir que a natureza apresenta

\footnotetext{
${ }^{2}$ A difusão dos centros politécnicos pela Europa, buscava suprir a necessidade de mão de obra militar qualificada para a época, visando manter no poder as monarquias absolutistas, tenebrosas com à ascensão ao poder da burguesia, ou mesmo expandir os impérios para outros reinos. Diante disso era importante o emprego de tecnologias para o melhoramento dos armamentos, sendo empregados as máquinas.
}

Recebido em: 25/05/2020

Aceito em: 19/09/2020 
uma reserva de energia que não é aumentado e nem reduzido, possibilitando à conclusão de que a energia na natureza não sofre alteração, bem como, a quantidade de matéria (CALADO, 2011).

Diante desse cenário era comum o emprego de cientistas nos centros politécnicos que eram os centros acadêmicos mais prestigiados do reino, e um desses professores que trabalhava em um centro politécnico na Prússia que englobava regiões da atual Alemanha e da Polônia foi Rudolf Julius Emmanuel Clausius. Este cientista estudou os fenômenos envolvidos com o calor, partindo inicialmente da análise de uma extensa literatura já produzida acerca da natureza do calor. Obtendo então que durante o trabalho realizado pelas máquinas térmicas este não resulta apenas no deslocamento de calor da fonte quente para a fonte fria, resultado ainda no consumo de calor. Desta forma o calor pode ser gerado pelo trabalho mecânico, sendo impossível realizar um processo cíclico visando unicamente transferir calor entre um corpo mais frio para um mais quente.

Willian Thomson contribui com essa discussão ao desenvolver os aportes matemáticos para os conceitos de irreversibilidade e dissipação do calor. Sendo obtida formulação mais estruturada para o valor de equivalência que representava o fluxo entre um corpo quente para um corpo frio, provocando a transformação do calor em trabalho, no qual está, é equilibrada pela conservação de trabalho em calor, de tal forma que o calor fluía entre um corpo frio para um quente. Portanto munidos de tais avanços conceituais Clausius, compreendeu a distinção nos processos reversíveis e os irreversíveis. Clausius ainda propôs a substituição do valor de equivalência que assumia uma quantificação positiva pela entropia: Em qualquer transformação que se produza num sistema isolado, a entropia do sistema aumenta ou permanece constante. Não há, portanto, qualquer sistema térmico perfeito no qual todo o calor é transformado em trabalho, existe sempre uma determinada perda de energia (BASSALO; FARIAS, 2015).

\section{CONSIDERAÇÕES FINAIS}

O produto didático apresentado neste artigo trata-se de uma sequência de ensino testada no âmbito de aulas do Ensino Médio e que foi incorporado melhorias após a sua utilização nas aulas apresentado em uma dissertação. Assim sendo, os docentes poderão utilizar de forma integral ou adaptar o presente artigo conforme os seus objetivos 
didáticos, bem como, podem determinar o grau de profundidade que desejam utilizar possibilitando assim o Ensino da Termodinâmica de forma interdisciplinar, demonstrando como ocorreu a construção dessa teoria e de seus impactos na sociedade. Além disso o texto permite demonstrar a ciência como um processo de construção humana passível de influências do seu contexto tais como a necessidade social de aperfeiçoamento das máquinas térmicas.

\section{REFÊNCIAS}

ALlCHIN, D. Pseudohistory and Pseudoscience. Science Education. v.13, n. 3, p. 179-195, 2004.

ALVIM, M, H.; ZANOTELLO, M. História das ciências e educação científica em uma perspectiva discursiva: contribuições para a formação cidadã e reflexiva. Revista Brasileira de História da Ciência, v.7, n.2, p. 349-359, 2014.

BASSALO, J, M, F.; FARIAS, R, F. Clausius: pequena história da entropia. História da Química, v.10, n.2, p. 95-100, 2015.

BERNAL, J. D. Science in History. Vol. 2: The Scientific and Industrial Revolutions. Londres: Pengum Books, 1951.

CALADO, J. Haja Luz: Uma História da Química através de tudo. Lisboa: Ist Press, 2011.

CARVALHO, A. M. P.; GIL -PÉREZ, D. Formação de professores de ciências: tendências e inovações. São Paulo: Cortez, 2011.

DÍAZ, S, M, F. Sadi Carnot y La Segunda Ley de La Termodinámica: La História de la Ciencia como Pedagogía Natural. 2014. 76f. Tese de Doctor en Educación. Programa Interinstitucional en Educación, Universidad Pedagógica Nacional, Bogotá, 2014.

EL-HANI, C, N. Notas sobre o ensino de História e Filosofia da Ciência Na Educação Superior. In: SILVA, C.C. (ORG). História e Filosofia da Ciência no Ensino de Ciências: Da teoria à sala de aula. São Paulo (Brasil): Editora Livraria da Física, p. 321, 2006.

FORATO, T, C, De M.; PIETROCOLA, M.; MARTINS, R, de, A. Historiografia e Natureza da Ciência na Sala de aula. Caderno Brasileiro de Ensino de Física. v.28, n.1, p.27-58, 2011. 
FOUREZ, G. A interdisciplinaridade em sentido estrito. In: FOUREZ, G; MAINGAIN,

A, DUFOUR, B. Abordagens didácticas da interdisciplinaridade. Lisboa: Instituto Piaget, 2008 Cap. V, p. 69 -80.

FREITAS, R, de, O. et al. Máquinas a vapor e a Revolução Industrial, 2014. Disponível em: https://otaviobatista.files.wordpress.com/2014/03/001-mc3a1quinas-avapor.pdf. Acesso em: 21/11/2017.

GIL-PÉREZ, D. et al. Para uma imagem não deformada do trabalho científico. Ciência e Educação. v.7, n.2, p. 125-153, 2001.

HOBSBAWM, E, J. Da Revolução Industrial inglesa ao imperialismo. Tradução: Donaldson Magalhães Garschagen. 5 ed. Rio de Janeiro: Forense Universitária, 2000.

LEÃO, D, M, M. Paradigmas contemporâneos de Educação: Escola Tradicional E Escola Construtivista. Cadernos de Pesquisa, s/v, n. 107, p. 187-206, 1999.

LIMA, E. C. De.; OLIVEIRA NETO, C. R. De. Revolução Industrial: considerações sobre o pioneirismo industrial inglês. Revista Espaço Acadêmico, v. 17, n. 194, p. 102113, 6 jul. 2017.

LHULLIER, F, D. A vigência das cláusulas normativas dos acordos e convenções coletivas de trabalho. $66 \mathrm{f}$. Trabalho de Conclusão do Curso de Direito, Universidade Federal de Sant Catarina, Florianópolis, 2013.

MATTEWS, M, R. História, Filosofia e Ensino de Ciências: A Tendência Atual de Reaproximação. Caderno Brasileiro de Ensino de Física. v. 12, n.3, p. 164-214, 1995.

MCCOMAS, W, F. The Principal Elements Of The Nature Science: Dispelling The Myths. Science \& Education. v.7, n.6, p. 511-532, 1998.

MOURA, B, A.; SILVA, C, C. Abordagem multicontextual da história da ciência: Uma proposta para o ensino de conteúdos históricos na formação de professores. Revista Brasileira de História da Ciência. v. 7, n.2, p.336-348, 2014.

MOURA, C, B.; GUERRA, A. História cultural da ciência: Um caminho possível para a discussão sobre as práticas científicas no ensino de ciências? Revista Brasileira de Pesquisa em Educação em Ciências. v. 16, n. 3, p. 725-748, 2016.

PÁDUA, A, B, de.; PÁDUA, C, G, de.; SILVA, J, L, C. A história da Termodinâmica Clássica: Uma Ciência Fundamental. Londrina: EDUEL, 2009.

PASCOAL, A, dos, S. A evolução histórica da máquina térmica de Carnot como proposta para o Ensino da segunda lei da Termodinâmica. 2016. 142f. Dissertação

Recebido em: 25/05/2020

Aceito em: 19/09/2020 
de Mestrado em Ensino de Ciências e Educação Matemática, Centro de Ciências e Tecnologia, Universidade Estadual da Paraíba, Campina Grande, 2016.

OLIVEIRA, R, M, de. Revolução Industrial na Inglaterra: Um Novo Cenário na Idade Moderna. Revista Científica Multidisciplinar Núcleo do Conhecimento. v. 1, n. 2, p 89-116, 2017.

SANTOS, L, A. A Revolução Industrial. (2004). Notas de aula. Disponível em: https://slidex.tips/download/aula4-a-revoluao-industrial-lenalda-andrade-santos. Acesso em 27/07/2018.

SANTOS, M. Uso da História da Ciência para favorecer a compreensão dos estudantes do Ensino Médio sobre ciência. Revista Brasileira de Pesquisa em Educação em Ciências. v. 18, n. 2, p. 641-668, 2018.

SILVA, G, R. da.; ERROBIDART, N, C, G. Ilha de Racionalidade Interdisciplinar aplicado à construção de uma representação histórica contextual sobre as máquinas térmicas. Revista Insignare Scientia. v. 3, n. 2, p. 49-63, 2020.

SOUZA, R, da S.; SILVA, A, P, B, da.; ARAUJO, T, S. James Prescott Joule e o equivalente mecânico do calor: Reproduzindo as dificuldades do laboratório. Revista Brasileira de Ensino de Física, v. 36, n. 3, p. 3301-3309, 2014.

SUÁRES, M, J. Estudio del impacto de los conceptos fundamentales de la Termodinámica em el desarrollo de la máquina térmica y el surgimento de la revolución industrial. 2011. 75f. Maestría em Enseñanza de las ciencias exactas y naturales. Facultad de Ciencias, Universidad Nacional de Colombia, Medellin, 2011.

TAVARES, L, A. James Watt: A trajetória que levou ao desenvolvimento da máquina a vapor vista por seus biógrafos e homens de ciências. 2008. 74 f. Dissertação de Mestrado em História da Ciência, departamento de Educação, Pontifica Universidade Católica de São Paulo, São Paulo, 2008.

Recebido em: 25/05/2020

Aceito em: 19/09/2020 